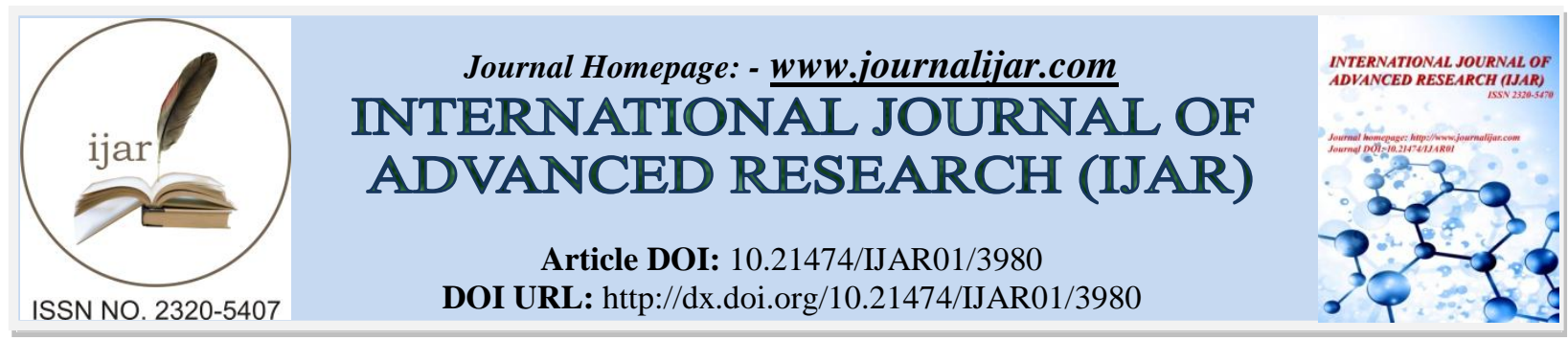

RESEARCH ARTICLE

\title{
INTEGRATION OF INDOOR ENVIRONMENTAL ANALYSIS IN ARCHITECTURAL LANDSCAPE DESIGN.
}

Emad Al Dein Hasan Al Fahmawee

Applied Science Private University, Faculty of Art and Design, Amman, Jordan.

\section{Manuscript Info}

Manuscript History

Received: 23 February 2017

Final Accepted: 19 March 2017

Published: April 2017

Key words:-

Atrium building, Indoor landscaping, Environmental analysis, People need analysis, Landscape design.

\begin{abstract}
The importance of this study is to create an ideal indoor landscaping design in atrium buildings, by investigating environmental conditions, both the thermal and daylighting performances in glazed roof atria of Taj Mall in Amman. For these, environmental measurements, as well as site and people need analysis have been conducted. This study is based on the results of a previous research (Al-Fahmawee, 2013), the results provide evidence of strong co-relation between floor height and daylight performance inside atria. Based on the information gathered from the site analysis, and indoor environmental evaluation mentioned in (Al-Fahmawee,2013), a final applied design were created for the three mall atria, taking into account client like and dislike according to the results of both interviews and questionnaire. This research could be useful for designer to estimate client preferences, to compute accurately the interior available daylight and to determine the ideal atria indoor landscaping design.
\end{abstract}

Copy Right, IJAR, 2017,. All rights reserved.

\section{Introduction:-}

Recently the laws and regulations of the Greater Amman Municipality impose a percentage of permitted building area, whether residential or commercial building, ranging from $39 \%$ to $50 \%$. As a result, many architects in Jordan tend to exploit the remaining space of the land to find an internal space in the building in the form of atrium, where they are not calculated among the enclosed spaces; consequently these buildings have become desirable among many investors and users.

Atrium building is considered carrying some special characteristics which appeal building designers and owners' attention so that the frequency of application is rather high and there is a trend of increasing (Hung, 2003). Capital cost of an atrium building was estimated lower than the conventional building by using less construction elements, fewer elevators and staircases, shorter construction time and hence smaller influence by inflation. In addition, investment value and revenue cost are the major appeals to the developers (Saxon, 1986). Atrium is a Latin word originally referring to a main room or central court with hearth, which caused the room walls to be covered with black soot (ater) though time, giving it its name (atrium) in a typical ancient Roman house (Moosavi et al, 2014), but today the term atrium is typically associated with commercial or public buildings.

An atrium is usually a high interior covered by a glass roof and walls surrounded by several storey's or galleries, today's atrium is defined by its geometry, the physical characteristics of its fenestration, and the physical characteristics of the wall between the atrium and the adjacent spaces (Abdullah et al, 2009). Atrium performs 
impressive spaces, revives the indoor space by admitting daylight, maximizes the benefit from direct solar gain, maintains solutions for natural ventilation and acclimatization, and increases interaction and socialization of the people (Saxon, 1986). A good indoor environment is significant to the success of a building, not only because it will decide its energy consumption and thus influence its sustainability in terms of energy but also because it will make its occupants comfortable (Sharma and Ali,1986 and Humphreys and Nicol, 2000). There are currently tendencies to make these buildings green by planting, indoor plants can increase positive affect as well as psychological benefits such as increased pain tolerance and stress-reduction. 'Green buildings' are promoted in developed countries at the end of the last century. Now, this term is extended to 'sustainable buildings' (Pettersen, 2002).

Distinctive landscaping is very often the key to a visually successful atrium. Interior landscape is a good way for making a connection between indoor and outdoor environments (Calcagni and Paroncini, 2004). Interior scaping is the "fusion of architecture with the landscape" (Rose, 1938). The indoor landscape enhances the entrance of the building and contributes to the psychological well-being of people. Professional interior landscapers work with the owners of large buildings to introduce plants into both public and private spaces to enhance its utility. Bioclimatic design is needed to stratify human beings' need thermal, visual and acoustic (Vissilia, 2009). Any indoor environment is more pleasant and attractive when living plants are a part of the location. Actual enjoyment and consistent sensation with indoor plants depends on selecting the right plant for a right environmental circumstance. Light, temperature and humidity are key considerations.

Sufficient quantity of light is the strongest determinant or success in atrium planting. (Scrivens, 1980). It is important to link plants with the locations that satisfy their basic light necessities. The quality, intensity, and duration of light directly impact plant growth. Light is the most growth factor limiting indoor planting (Whiting et al., 2010). Temperature also plays an important role in the landscape's success. Planting should be held back from sources of cold air such as unprotected entries (those without a vestibule or revolving doors) cold spots due to uninsulated glazing and mechanical air distribution locations. In addition, direct sunlight should be avoided with most commonly grown interior plants (Scrivens, 1980).

It is axiomatic that landscaping and atria linked together in designer mind, landscaping is a major element in the creation of relaxing, effective living atrium. It is important to match plants with locations that satisfy their basic requirements. It can't be assumed that anything will grow in a basic light and temperature requirements. Unfortunately, through the study of a group of commercial buildings within Amman city, it was observed the presence of a large chaotic design in atrium building without returning to the atrium configurations (space, height, form) and the indoor environmental conditions which is the strongest determinant in atrium landscaping.

Therefore, this study is aimed to create an ideal landscape design in atrium buildings, by investigating environmental conditions, both the thermal and daylighting performances in glazed roof atriums and in the adjoining space. Taking into account the human comfort and needs that can be achieved by using the proposed questionnaire to find out how they want the atrium to look like.

\section{Methodology:-}

This research was based on studying and analyzing the daylight and thermal conditions in atria buildings in Amman, as well as clients' appreciation and their influence on atria landscaping, this was performed using two main phases; preparation and design.

\section{Preparation phase:-}

Site selection, site analysis, environmental conditions evaluation and people's needs analysis are the key steps in preparation phase.

\section{Site selection:-}

Taj Mall complex was selected for this study (figure 1), because it has three existing large atriums which have the same circular shape of different heights, sizes, and orientations (figure 2) as already mentioned in my previous research that make the comparison in indoor landscaping at different heights and orientation more efficient. All plans and drawings regarding the description of Taj Mall atria can access by return to (Al-fahmawee, 2013). 


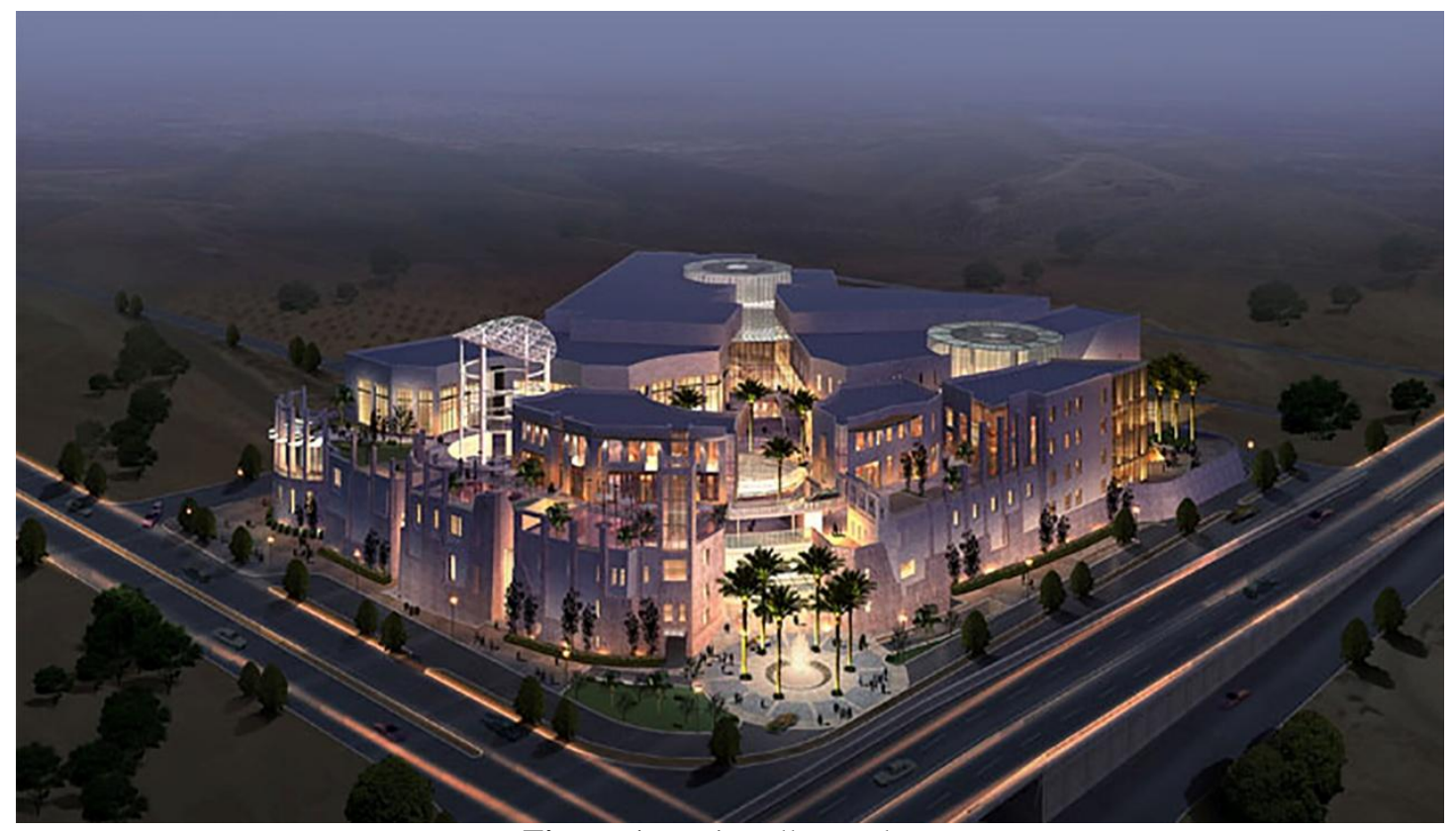

Figure 1:- Taj Mall complex.

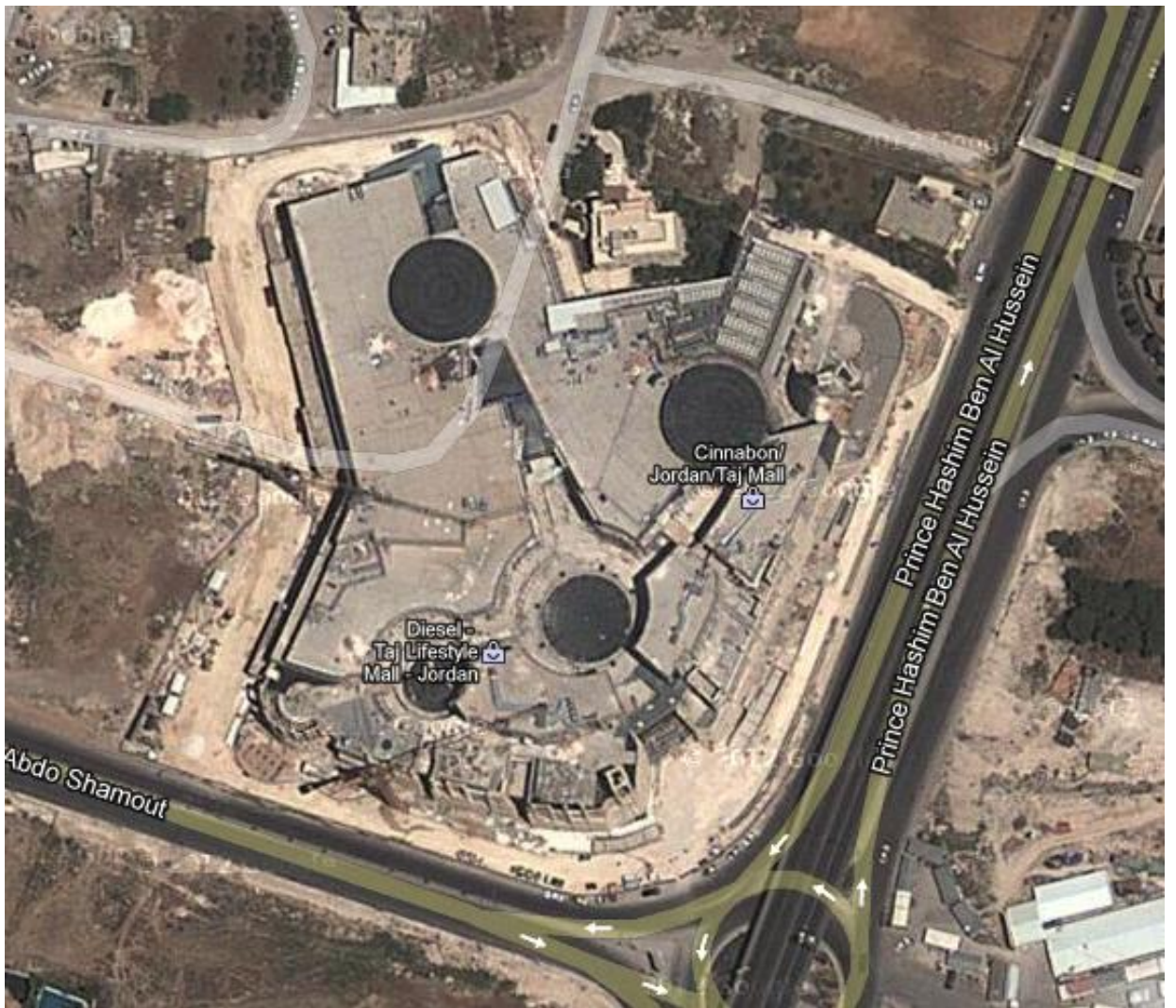

Figure 2:- The three atria of Taj Mall complex located in south-west of Amman.

\section{Site Analysis:-}

Site location and microclimate has an actual impact on the environmental design of an atrium building. Heating and cooling requirements within the atrium will be affected by the average external temperatures to keep indoor environment suitable. In addition, the sun's altitude in winter and summer will be influenced by the latitude of the site which, in turn, will affect the building's capacity to capture sunlight (Donnelley, 2007). 
The atrium building site has been visited several times to collect data about the average external temperatures, well size, floors height, interior configurations, sun orientation, light duration, and transmittance of the roof.

\section{Evaluation of indoor environmental Conditions:-}

Parametric measurements of daylight level and temperatures in the three existing large atria of Taj Mall complex in Amman have been conducted. The three atria have a circular shape of different sizes, heights and orientation.

\section{People's needs Analysis:-} Interview:-

Interviews were conducted with ten stores managers, storeowners, and investors in Taj Mall. The purpose of these interviews were: to gain a better understanding of the dwellers' interest in the mall, to gain additional insights into landscaping models or approaches currently being used, and to gain experience from professionals, who worked with individuals in the mall to find out what they want the atrium space to look like, and to make it more comfortable. The users will be asked to give their opinion about their specific stores and offices in terms of design, spacing and to state their personal satisfaction with their current buildings. A list of questions was asked during interviews.

\section{Questionnaire:-}

Questionnaires were distributed to sixty of store clients and visitors of the Taj Mall; it's created to achieve a landscape design, which fits people's needs and expectations. For the purpose of identifying measures which directly related to comfort of occupants, some techniques are recommended to include such as a questionnaire which includes a part of environmental elements, a part on personal behavior and a part on working conditions (Bluyssen, 2010).

\section{Design phase:-}

The design concept was based on the results of environmental analysis and the questionnaire .The final details of plants, materials, products and interior finishing were included in the final design plans.

\section{Conceptual Design:-}

The design concept followed by environmental factors and people need analysis. During the concept development rough drawings of the site, objectives, and functions are stated using landscape symbols. Concept design includes specifying (soft element) compose and arrange species of trees, shrubs, grasses, vines, bulbs, succulents and groundcovers depending on environmental requirements and client preferences. Also (hard landscape elements) a list of features, activities, and furniture were used according to client response.

\section{Final Designs:-}

This plan shows the exact layout of all elements and the materials were used. Detailed drawings, sketches, photos are provided. A special graphic computer programs for landscape design will be used to produce drawings of the interior landscaping design for the atria of the mall. Produce detailed scaled computer aided design (CAD) master plans showing landscape construction and setout detail, plant details and positioning and other relevant information.

\section{Results and Discussions:- Preparation phase:- \\ Site Analysis:-}

All data about the average external temperatures, well size, floors height, interior configurations, sun orientation, light duration, and transmittance of the roof was illustrated in (Al-Fahmawee, 2013).

\section{Evaluation of indoor environmental Conditions:- Thermal performance in different Atria:-}

The daily readings for average temperature are ranging from 18 degrees Celsius to 27 degrees Celsius in the three atria. There were no differences between the sensors readings in all heights as well as locations. This is due to the central air conditioning system used in the mall. 


\section{Daylight performance in different Atria:-}

The higher floors indicate higher lighting levels. Adequate lighting level can be achieved when as getting toward top floor. On the other hand, it can be observed that the south side has the highest daylighting performance compared to the other sides in the three atria. The results were more illustrated in the following reference (Al-fahmawee, 2013).

\section{People's needs Analysis:- \\ Interviews:-}

According to the answers of interview question, (80\%) of the mall dwellers prefer to modernize and develop the atria of the mall. About the benefit that can gain in the case of modernization and development of the mall atria, different views have been drawn:

$>$ For stores owner, in the case of modernization and development of atrium, it will be an attraction point and gathering more visitors, and if the number of visitors increase financial return would be better.

$>$ For the owners of restaurants and cafes, atrium will be an extension of the restaurant and cafes and additional space for them, so they could accommodate a larger number of clients and therefore get more profit.

$>$ For mall managers, the mall will be entertaining, more distinctive from other malls and therefore more visitors to the mall by adding functional luxuries.

People were asked about the preferred indoor landscaping elements that can be added to modernize this atrium, from the answers of questions the majority preferred the presence of some plants, especially palm trees, ornamental grasses, and flowers. And some preferred the presence of seats, tables, pergola, fountains, and other structures. Finally from the results of the interviews the idea of developing the mall is desirable and welcome; mall dwellers desire the atria improvement and development.

\section{Questionnaire:-}

Questionnaire was prepared based on subjective parameters like socio-economic and socio-cultural habits that may affect client needs and preferences. The same indoor conditions may lead to different subjective responses. One observable explanation is that people differ and therefore not all are contented by the same conditions (Frontczak and Wargocki, 2011).

People were asked about the preferred indoor landscaping elements that make atrium beautiful and more comfortable, from the answers to question number five, 35\% for Plants (softscape elements), 3\% non living elements (hardscape elemnts), and $62 \%$ both elements together. The preferred sofscape elements that were selected for atria design both flowering and foliage plants in a percent of $67 \%$.

According to the answers of the preferred color for flowering and foliage plants, $75 \%$ of people prefer variety of colors for flowering plants On the contrary, $63 \%$ for green foliage plants rather than colored one.

About the preferred location and potting for indoor plants in atrium, the answers were Place the plants on both middle and corners of atrium was the highest percent (46\%) fixed in a large floor-standing containers in a percent of $(56 \%)$ rather than movable small pots.

The highest percent for the preferred containers for indoor plants was for fiberglass container by(41\%) then ceramic containers by $(28 \%)$, clay containers $(20 \%)$,and the lowest percentage was $(11 \%)$ for plastic containers.

For the preferred hardscape elements used in atria scaping ,the highest percent was for sculptures, raised bed, and benches by percent (19\%),(18\%), and (17\%) respectively. Tables and visual path have the same percent (14\%) and the lowest structure is pedestrian bridges in a percent $(8 \%)$.

Wooden and rocky were the highest preferred materials for hardsape structure in a percent of (44\%) $(31 \%)$ respectively, and the lowest percent was (3\%) for plastic material.

The desirable furniture to use in atrium was (47\%) for both fixed heavy furniture and movable lightweight furniture. About the preferred lighting features used in atrium, direct light (spotlight), hidden light, wall mounted light, and up lighter have a percent of $(15 \%),(37 \%),(14 \%)$, and (34\%), respectively. 
People were asked about their willingness to have water features in atria design and In the case of desire, what is the preferred one. The results were $(95 \%)$ of people like to have water features in atrium. The most preferred one is wall waterfalls by a percent $(54 \%)$, followed by $(22 \%)$ for fountains.

The information gathered from the interviews and questionnaire was used to create a conceptual master plan for atria, taking into account the resultant environmental evaluation.

\section{Design phase:-}

The design process can be divided into two stages depending on the results of site, environmental, and people needs analysis, conceptual design and the final applied design.

\section{Conceptual Design:-}

In a concept plan, the basic elements (softscape elements, hardscap elements, tiling, and lighting) begin to take on specific shapes and characteristics, and how individual spaces will come together. The concept plan provides a starting point for designing the interior space of atria.

\section{Soft landscape Elements:-}

Choosing the right plants for the right situation is a key elements in successful indoor gardening ( Raworth and Bradley, 1998). All plants have different light requirements. So, in order to have successful interior plantscaping, light intensity in different locations was determined.

Plants were divided into sun, partial sun and shade base on their light requirements. Interior landscape design focuses on three key elements: texture, form and color (Hannebaum, 2002), commensurate with the design concepts: proportion, balance, rhythm, and dominance. Softer, textured plants, such as Ficus benjamina, are perfect for a traditional or classic look. More contemporary spaces require a hardier texture; Succulents and Dracaena marginata are good choices for these areas. Color is integrated into design with the use of variegated leaves and flowering plants. Flowers with a hint of blue or white in their makeup appear much cooler than that warm color with yellow or red. A toning display of white, pink or blue flowers can have a very calming effect. While yellow, red, or orange flowers were combined well to create a contrasting display (Raworth and Bradley, 1998).

\section{Hard landscape Elements:-}

In the main atrium a rocky sculpture was used, water fountain, colour gravel that fill the fountain base, as well as the raised bed planters that formed the greenery strap around the fountain containing seasonal flowering plants. Large wooden benches were installed in the seating area around the greenery strap. Small wooden benches were placed beside each palm in the square rest areas, while decorative built-in planters were arranged in the corresponding corner of the palm. A raised planter-beds and movable metallic seats were put in the Arab form star periphery.

For administration atrium, cascading waterfall was installed perpendicular to the escalator, small mosaic fiberglass containers stepping up waterfall slope. Small wooden benches were installed in the minor spaces between water channels, in addition to that large raised bed fiberglass planters were arranged in atrium circumferences.

In cinema ground floor water pool nozzle was installed parallel to escalator. Large movable fiberglass pots were put in the upper side of elevator edges. A large rock was placed in the central core of the atrium representing Imaginary Island. Island of simulated rock surrounded by built-in planters, as well as a bed stones framing the planted island. Small fiberglass raise bed planters with large wooden benches were distributed in atrium perimeter.

\section{Tiling:-}

Interlock tiles were used for the three atria to give the landscape character for the interior space. It has a rough brushed texture to prevent slipping, as well as its beige color to make a contrast with the landscape. Tiles were distributed in space surrounded by borders that have been developed in conceptual design to clarify and define the space. These borders formed the visual path in the interior space and the Arab form star in the main atrium. Glass mosaic tile were used for all water features base, as well as rough stones in the minor spaces between channels.

\section{Lighting:-}

Combining decorative lighting with plants (or by placing plants in a way that they interact with the lighting already in place) can produce some interesting effects and break up the sterile monotony of many large, open-plan spaces. Decorative lighting, such as low-voltage LED lights placed among the foliage of plants, could be considered as part of an interior landscape design (Freeman, 2011). Lighting has been revolutionized by the introduction of efficient 
LEDs, and the increased availability of relatively safe, low-voltage lighting and more reliable solar-powered units. It can be used as pool lighting, recessed lighting, twinkle lights, or spots, almost anywhere in the garden. More expensive to buy, but cost effective when efficiency and longevity are taken into account. LED Lighting features were placed in different atria locations according to their expected function. In main atrium fiber optic spot light was installed in fountain base. This lighting integrates colors in the form of overlapping waves. A hidden lighting was placed under benches that surround the fountain. In square rest areas spot light up walk were put in the corners, and three color projectors were installed under each palm in the opposite corner. Inside the planters next to the seats allocated on the circumference, three small projectors were distributed.

In administration atrium, fiber optic spot light has been placed in water feature steps next to planter beds cascading down them. Four spot light were installed in radial line along the water channels. Inside the planters next to the seats allocated on the circumference, three small projectors were distributed.

For the cinema ground floor fiber optic spot light has been installed along water pool nozzle base. Colored up lighters were put toward the rocky island to create sparkle effect in simulated rock. Wall mounted light was installed on the surrounding columns to a height of about $2.25 \mathrm{~m}$. For the cinema rooftop fiber optic spot light has been installed along water pool nozzle base as in ground floor, also five up lighters were placed in each island (raised bed planter). For the containers that placed on cinema stairs, two small projectors were fixed inside each one.

\section{Final applied Designs:-}

Once the final landscape design has been completed, scaled colour landscape plans will be presented in. figures $(3,4,5)$ representing the final applied design for the main atrium ground floor, administration ground floor, as well as cinema ground floor respectively. A written report on plant specifications, hardscape material choices, lighting and tiling was provided.

\section{For the main Atrium:-}

The ground floor of the atrium is the evident location for landscaping, but planting on the upper floors can also be effective. In the ground floor the central space here is circular and open for many quarters of its circumferences to the adjoining space. In the center of the atrium water fountain was created surmounted by sculpture, it's enclosed by vegetarian strap containing seasonal variations in bedding out plants and flowering species. Seating area surrounding the greenery strap making the central core as a point of magnificent attractiveness and people centered environment. In addition to that, square rest areas were distributed in a harmonious way toward the circumference, where planters of palms were put in the corner of each square. Beside each palm benches were installed, while decorative planting beds were arranged in the corresponding corner of the palm. The corners of the squared rest areas inspire Arab form star in the central core. A harmonious distribution of raised planter-beds and movable seats were taken in the Arab form star periphery. Seasonal flowering plants, shrubs, and small trees fill the planter surfaces (Figure 3). 


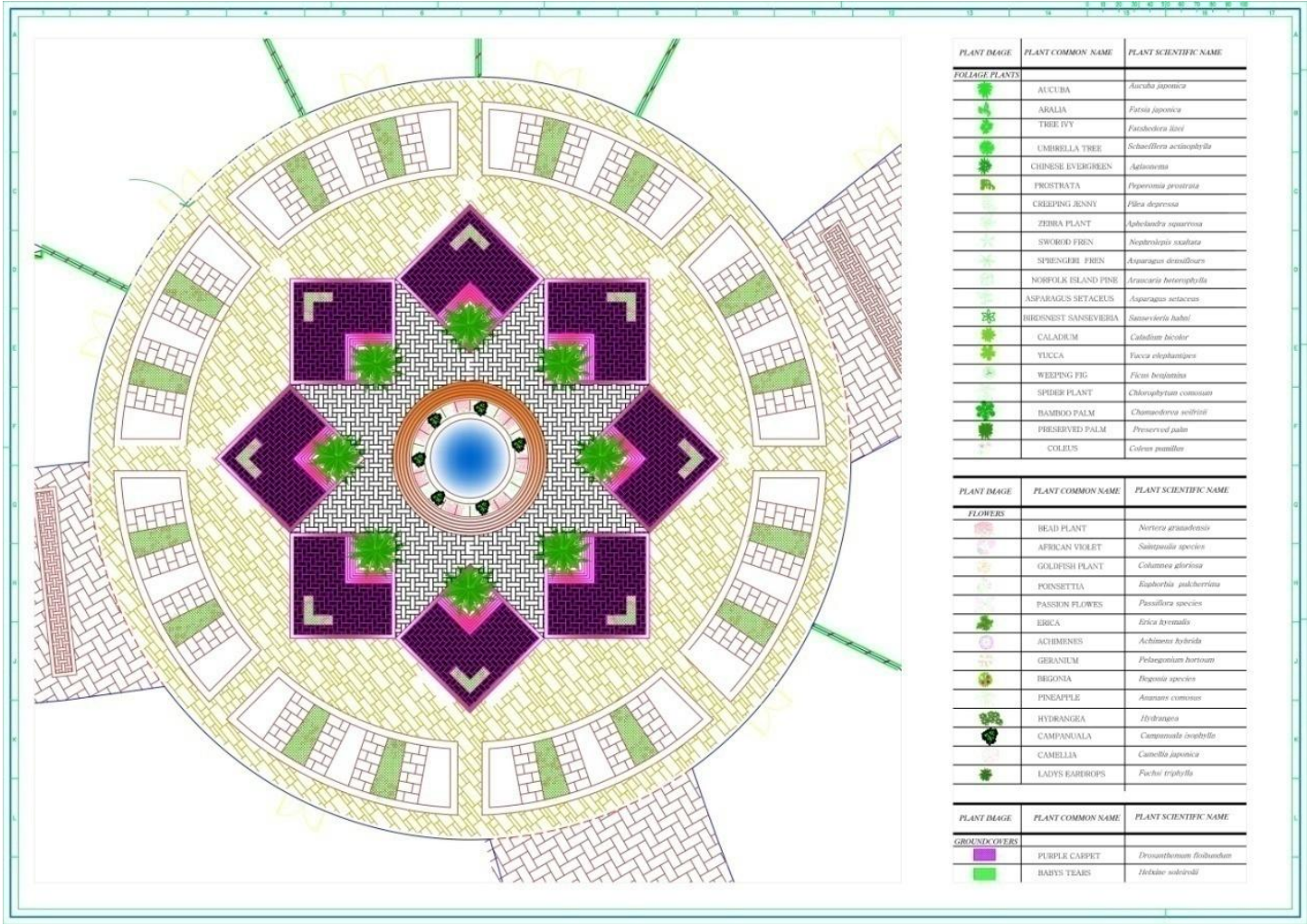

Figure 3:- Concept plane for the ground floor of the main atrium

\section{For administration Atrium:-}

The concept plan for the ground floor of administration atrium was shown in (Figure 4). The available space to be designed in this atrium is about half circle. The center of the circle has been adopted to form the dominant element of the interior design. Radial lines have been drawn from the center of the circle toward its circumference, these radial lines dividing the main space to minor spaces. On the axis of the central point of the circle, cascading waterfall was installed perpendicular to the escalator. With water cascading down, containers set rows of ornamental grass stepping up the slope. The water feature is orientated to face the centre of the atrium where seating is intended. Waterfall surrounded by a ring of greenery of flowering annuals and perennial that absorb conversation noise and give degree of calm and serenity to the place. Water channels have been designed on the radial lines, the minor spaces between channels filled by seating areas. A graceful evergreen shrubs and trees were installed in ornamental containers at the circumference surrounding seating areas. 


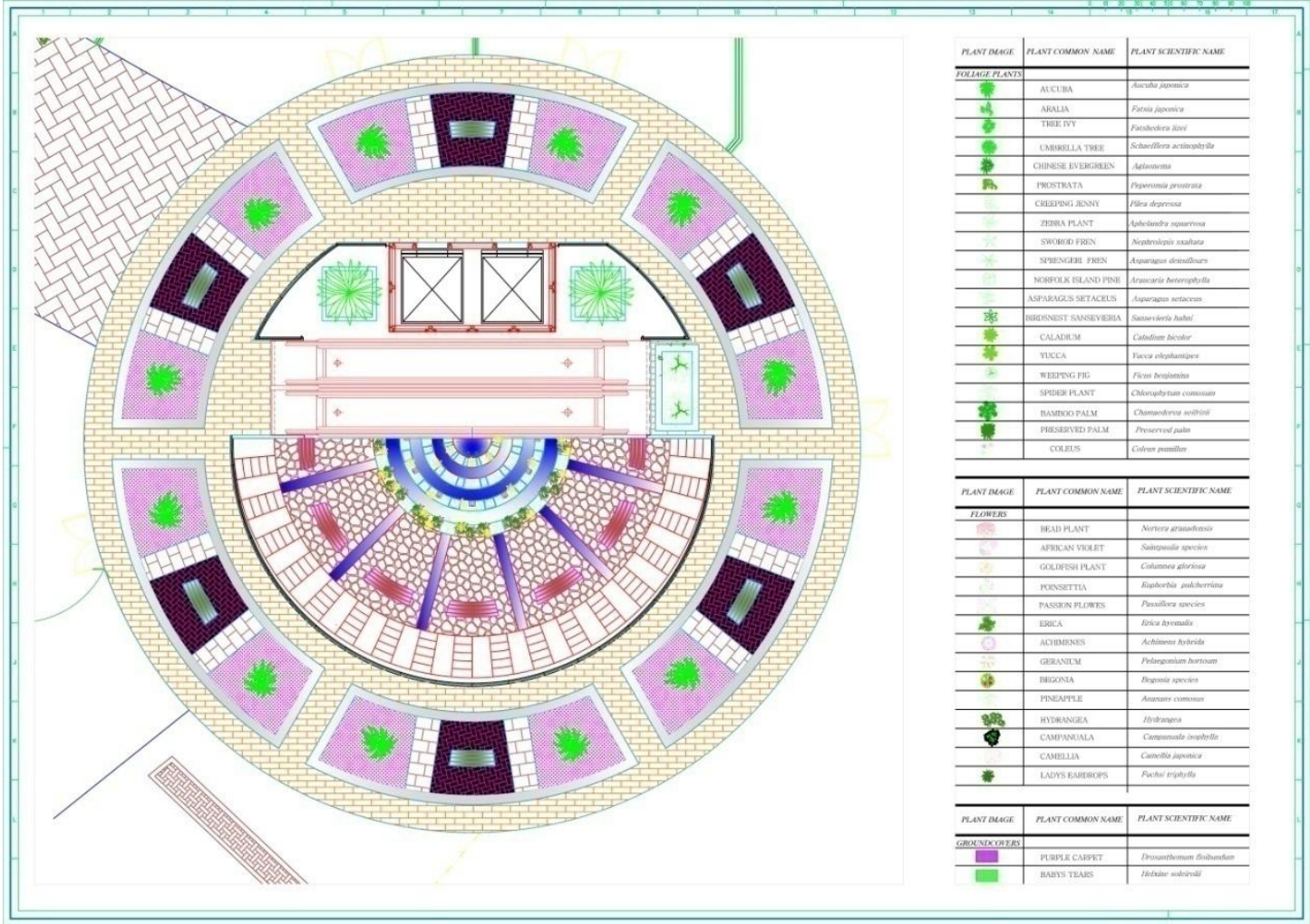

Figure 4:- The concept plan for the ground floor for administration atrium.

\section{For cinema Atrium:-}

As shown in figure (5), planting in cinema ground floor is not fully successful; it's insufficient to light with minimal court size, and compact floor space of a four stories. Based on these circumstances, proposal design was created. Water pool nozzle was installed parallel to escalator. Large trees in movable pots were put in the side of elevator. In the central core an island of simulated rock surrounded by rippling flowering plants with contrasting climbing foliage plants rambling over rocks. This planted island flanked by a bed stones forms a rich romantic focal point in the atrium. In addition to that, flowering and foliage plants were distributed in multiple planters harmoniously with a number of benches on the circular perimeter. The multiple planters have planting units with different levels. The lowest unit composes of bands of seasonal flowering plants which last only a few weeks, and then it's replaced by new bands throughout the year to give a colorful emphasis. Finally the tallest units provide a permanent greenish view of foliage plants. 


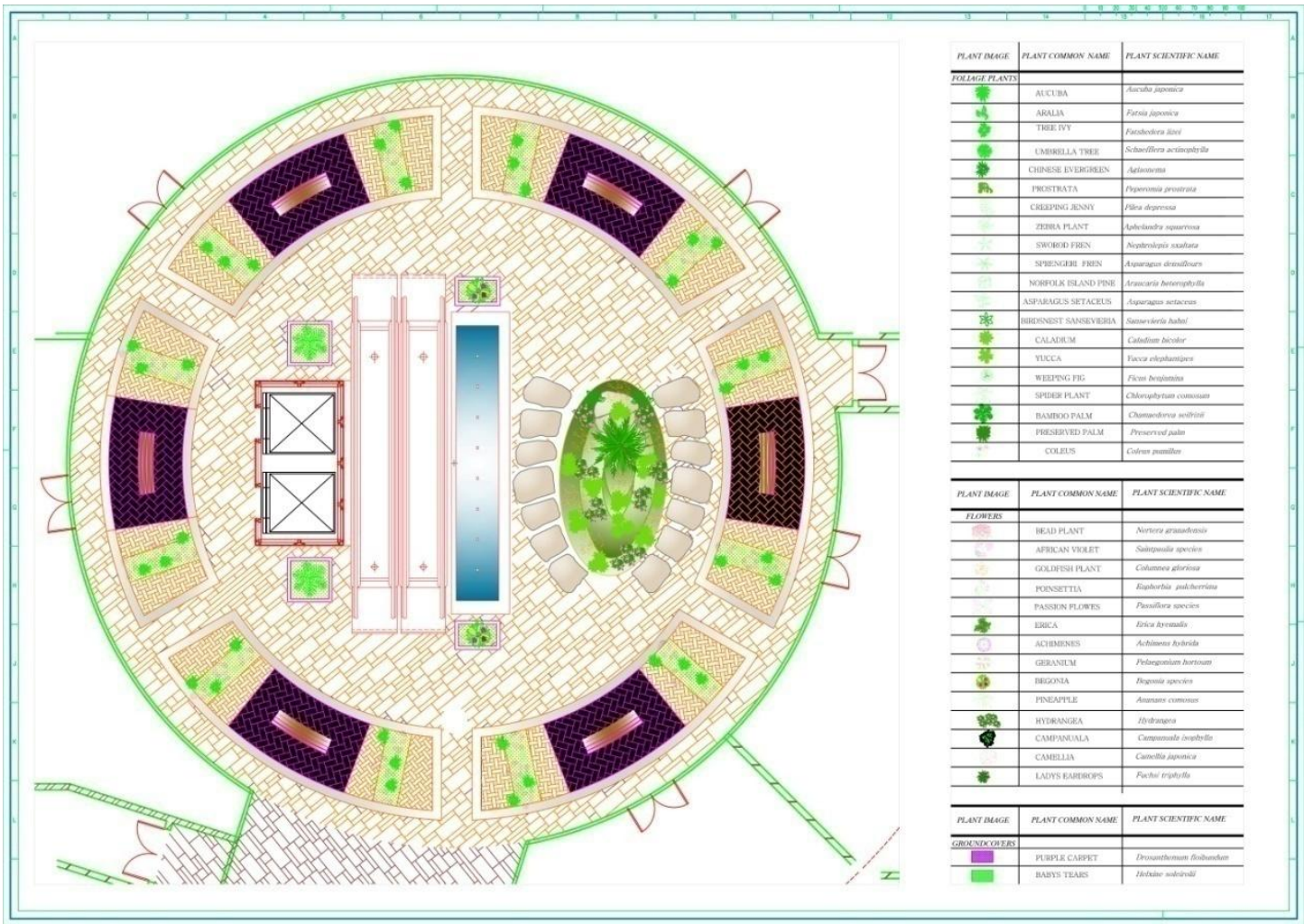

Figure 5:- The concept plan for the ground floor for cinema atrium

\section{Conclusions:-}

This study is based on thermal and daylight measurements and its impact on atria indoor landscaping. It clearly represents more detailed understandings of interior environments of Taj mall atria in Amman at different climatic zones. Extensive parametric measurements of thermal and daylight level have been conducted at various floors heights, and in different locations in the same floor using precision sensors. It has been found that there were no differences in thermal performance in all heights as well as locations of atrium, this is due to the central air conditioning system used in the mall. Otherwise considerable discrepancies were observed among the daily measured daylight parameters at various heights as well as locations. Light intensity has a linear relationship with floor heights in the three different atria. It can be concluded that there is a correlation between floor height and atria available daylight. From the results, the upper floors and the south side have the highest daylighting performance compared to the other sides in the three atria. Based on information gathered from the site, environment, and peoples need analysis, final applied design for atria interior space were created, all hardscaping, softscaping elements, and positioning were determined.

\section{References:-}

1. Alfahmawee, E.H. , ( 2013), Analyzing the Impact of Floor Height and Building Orientation on Atria Daylighting Levels. Jordan Journal of Applied Science, 11:75-88.

2. Bluyssen, P., (2010), Towards New Methods and Ways To Create Healthy And Comfortable Buildings, Building and Environment, 45: 808-818.

3. Donnelley, R.R., (2007), School design: Optimizing the internal environment, Scottish Executive, Edinburgh.

4. Frontczak, M. and Wargocki, P., (2011), Literature Survey On How Different Factors Influence Human Comfort In Indoor Environments, Building and Environment, 46: 922-937.

5. Hannebaum, L., (2002), Landscape Design: A Practical Approach, (5 editions), Reston, Virginia, United States: Prentice Hall.

6. Raworth, J. and Bradley, V. , (1998), The Complete Guide to Indoor Gardening (first edition), Abbeville Press Publishers, New York.

7. Rose, J., (1938), Integration. Pencil Points: 67-87.

8. Saxon, R., (1986), Atrium buildings development and design, 2nd edition, The Architectural Press London. 
9. Scrivens, S., (1980), Interior Planting In Large Buildings. The Architectural Press Ltd: London.

10. Vissilia, A.M. , (2009), Bioclimatic Lessons from James C. Rose's Architecture. Building and Environment, 44: $1758-1768$.

11. Hung, W.Y, (2003), ARCHITECTURAL ASPECTS OF Atrium International Journal on Engineering Performance-Based Fire Codes, 5: P.131-137

12. Moosavi, L., Mahyuddin, N., Ab Ghafar, N, Ismail, M.A. , (2014), Thermal performance of atria: An overview of natural ventilation effective designs, Renewable and Sustainable Energy Reviews, 34: 654-670.

13. Abdullah, A., Meng, Q., Zhao, L., Wang, F., (2009), Field study on indoor thermal environment in an atrium in tropical climates, Building and Environment 44: 431- 436.

14. Freeman, v., (2011), Ambius White Paper, Ambius University publication, USA

15. Calcagni, B. and Paroncini, M., (2004), Daylight Factor Prediction In Atria Building Designs, Solar Energy, 76: 669-682.

16. Humphreys, M.A. and Nicol, J.F., (2000), Adaptive Thermal Comfort And Sustainable Thermal Standards For Buildings, Energy and Buildings, 34: 563-572.

17. Sharma, M.R. and Ali, S., (1986). Tropical Summer Index- A Study of Thermal Comfort in Indian Subjects. Building and Environment, 21 (1): 11-24.

18. Whiting, D., Roll, M. and Vickerman, L., (2010), Plant Growth Factors: Light, Colorado State University Extension, Colorado master gardener, Colorado.

19. Pettersen, T.D., (2002), Sustainable Building, Proceedings of the Third International Conference on Sustainable Building, Oslo. 